\title{
DESAJUSTES ENTRE NÍVEL DE RENDA E HIERARQUIAS SIMBÓLICAS EM COMODORO RIVADAVIA. SOBRE AS LEGITIMIDADES DA DESIGUALDADE SOCIAL*
}

Alejandro Grimson

Brígida Baeza

Os pobres, às vezes, têm mais dinheiro que os ricos em Comodoro Rivadavia. Os trabalhadores do petróleo, socialmente considerados "negros", ainda que não tenham nenhuma ascendência afro, têm rendas mensais que superam as de muitos profissionais ou comerciantes da mesma cidade. Por isso, interessados nas desigualdades sociais e nos modos pelos quais elas se legitimam culturalmente, aprofundamo-nos neste estudo de caso. A nosso ver, um caso excepcional como o de Comodoro nos revela aspectos dos casos supostamente normais, nos quais as hierarquais de prestígio são mais ou menos proporcionais aos níveis de renda. Em segundo lugar, nos permite perceber que os casos em que esta correlação não se verifica são mais usuais do que o registrado nos estudos atuais. Em terceiro lugar, possibilita obter uma conclusão sociológica com implicações políticas: a redistribuição econômica é uma condição necessária, mas não suficiente para a redução multidimensional da desigualdade.

No caso particular que analisamos, encontramos uma situação de desajuste extremo entre o capital econômico que os trabalhadores petroleiros não hierárquicos possuem - fornecido por seus altos salários - e seu prestígio social que, para outros setores não petroleiros, está representado por um escasso capital cultural e social, a ponto de se tratar de um grupo com alta renda econômica e sob forte estigmatização. ${ }^{1}$ Este fato é socialmente legitimado através de diversas teorias nativas da desigualdade. Estas teorias acentuam a falta de ascetismo por parte dos petroleiros, fornecem explicações e recriminações morais ao estilo de suas famílias e legitimam, através de diversas situações problemáticas, a persistência de fortes estigmas em relação aos petroleiros e a elas. O fato de que essas teorias nativas legitimam desigualdades em relação a um grupo com alto nível de renda obriga 
a reposicionar certas análises e debates sobre a sociogênese e a persistência das desigualdades sociais, questão que retomaremos nas conclusões deste artigo.

Comodoro Rivadavia está localizada na costa atlântica, mas seu caráter de cidade portuária é apenas subsidiário de sua principal fonte produtiva: o petróleo extraído de jazidas localizadas nas zonas altas da Meseta Patagónica. A descoberta do petróleo na Argentina ocorreu em 1907, pouco depois da criação da cidade, e foi gerando processos sociais associados a esta exploração. Comodoro converteu-se na cidade mais povoada da Patagônia junto com Neuquén, alcançando na atualidade cerca de 200 mil habitantes. ${ }^{2}$

Nos cem anos desde que se descobriu petróleo até hoje, houve momentos muito diferentes, estreitamente ligados a dinâmicas econômicas e às políticas de Estado. Na década de 1920, criou-se a Yacimientos Petrolíferos Fiscales, que foi crescendo ao longo do século até converter-se em uma empresa pública com explorações em diferentes regiões do país, que oferecia a seus trabalhadores uma grande quantidade de benefícios sociais (acesso a moradia, férias, saúde, educação etc.). A partir de 1990, introduziram-se reformas neoliberais que acabaram com a "velha YPF" e culminaram com sua privatização. Durante esse processo, milhares de empregados foram afetados e os benefícios sociais desapareceram. O termo "ypefiano" começou a se referir a um evento do passado e, com os anos, o sindicato dos petroleiros privados passou a ser identificado simplesmente como petroleiros. A situação dos petroleiros de Comodoro evoluiu do apogeu à crise em função dos preços do petróleo. No último quinquênio verificou-se um crescimento sustentado.

Os estudos e os ensaios sobre Comodoro podem ser agrupados em três grandes correntes. Por um lado, temos a perspectiva que realça o valor geopolítico da cidade petroleira na Patagônia (Moreno 1985); por outro, há uma série de ensaios que aludem à "sociedade doente" e que ressaltam a ideia de "anomia", de "desenraizamento e depressão" (Budiño 1971; de Boer 1993). Por fim, cabe mencionar as investigações estritamente acadêmicas que abordaram questões migratórias (Mármora 1968; Torres 2001; Baeza 2006), diversos aspectos vinculados ao mundo petroleiro da primeira metade do século XX (Torres 1995, 2001; Marques \& Palma Godoy 1993, 1995; Crespo 2009; Carrizo 2007) e a conformação política da região (Barros 2009; Carrizo 2010).

Na cidade em que se descobriu o petróleo, o termo petroleiro só se tornou uma categoria de identificação relevante nos últimos anos. Primeiro, porque a empresa estatal YPF (Yacimientos Petrolíferos Fiscales) constituiu durante décadas uma categoria de identificação para seus trabalhadores, 
denominados ypefianos. Os ypefianos eram petroleiros, mas também outras categorias de empregados da empresa: pessoal administrativo, operários, gerentes, empregados do cemitério, de hospitais, de espaços recreativos, do supermercado ou de outras atividades própias da YPF. Os ypefianos tinham acesso privilegiado ou único a estes serviços e instituições. Segundo, porque diferentemente das company towns da YPF, sempre houve em Comodoro um maior nível de diversificação produtiva, incluindo a criação de gado, a pesca, o comércio e outras atividades. Esta tensão entre cidade petroleira e cidade com atividade petroleira permitiu o desenvolvimento de outros imaginários sobre o que seja Comodoro, qual o lugar do Estado e qual o lugar dos trabalhadores petroleiros.

Assim como não se usava o termo petroleiro como uma identidade social referida aos trabalhadores, também não há na cidade homenagens nem monumentos a eles. O único monumento aos trabalhadores que ela teve estava situado em frente ao edificio do SUPE (Sindicato Unido de Petroleiros del Estado), atingido pela deterioração e o abandono até seu total desaparecimento. Tal monumento é dedicado ao General Mosconi, protagonista da gesta petroleira e alto representante da empresa, que absorveu em seu interior uma série de categorias sociais. A Yacimientos Petrolíferos Fiscales desenvolveu explorações desde o princípio do século, gerando em muitos casos cidades que viveram exclusivamente do petróleo em Salta, Neuquén, Santa Cruz e em outras zonas do país.

Na pequena cidade de Río Turbio, na região de cordilheira ao sul de Santa Cruz, onde se produz carvão, o termo mineiro foi e continua sendo o que marca o epicentro da vida social. Antes de se tornar uma cidade, foi um acampamento mineiro, depois uma cidade mineira, cuja avenida central é denominada hoje de "dos Mineiros".

Cabe esclarecer aqui que os petroleiros são atualmente os trabalhadores assalariados mais numerosos da cidade fora os do setor de serviços, mas de modo algum poderiam ser considerados o escalão mais baixo das hierarquias simbólicas. Outro setor muito numeroso de trabalhadores assalariados é o dos operários da construção, alguns ligados à atividade petroleira, outros, à atividade tradicional. Entre eles e entre trabalhadores formais e informais de diversos tipos, há também numerosos imigrantes de países limítrofes e do norte do país, cujo direito a tudo (a trabalhar, a uma casa, a viver sua vida em Comodoro) é muitas vezes discutido e questionado pelos nascidos e criados na cidade. Os NYC (nascidos e criados na cidade)* são uma categoria

* [N.T.] Em espanhol, "nacidos y criados". 
central da vida social, que pressupõe que haja ou que deveria haver certos privilégios para aqueles que são verdadeiramente do lugar. Este artigo não investiga os setores mais deslocados de Comodoro, mas sim as tensões que se produzem sobre aqueles que se encontram no foco de certa instabilidade estrutural e das ambivalências identitárias sobre o que seja Comodoro.

O estudo de caso aqui apresentado tem alguns aspectos mais ou menos clássicos: baseia-se em entrevistas qualitativas, em observações de diversas situações sociais, na revisão de dados estatísticos e em trabalhos em arquivos. Sua peculiaridade é que enquanto o coautor mora em Buenos Aires e viajou em diferentes momentos para realizar esta investigação, a coautora mora há vinte anos em Comodoro Rivadavia, nasceu na província de Chubut e já havia iniciado estudos de pós-doutorado sobre outros temas de Comodoro. A questão distanciamento/familiarização, tão importante para o trabalho antropológico, teve aqui uma modalidade distinta. Além disso, contribuiu para um estudo em que dimensões de gênero são tão centrais, o fato de podermos complementar nossos papéis no trabalho de campo.

\section{Um espaço urbano segmentado}

Comodoro tem uma trama urbana muito peculiar, que dá conta também de aspectos de sua trama social. É uma cidade com $36 \mathrm{~km}$ de extensão. A palavra "comodoro" pode referir-se a toda esta extensão ou, em certos casos, especificamente à zona central da cidade, ao centro comercial e cívico que divide a cidade. Ali se concentram a administração estatal e a maior parte do comércio.

O conjunto da zona norte possui particularidades ligadas à trama fundacional da cidade. Nesta região, os bairros têm como nome a quantidade de quilômetros que os separa do centro. A YPF construiu seu bairro no "quilômetro 3". Outras empresas petroleiras que chegaram depois também construíram bairros próprios. A cidade foi adquirindo uma distribuição espacial particular, onde está plasmada a dinâmica da exploração petrolífera, das estradas de ferro, da exploração de cimento e da pesca.

Comodoro, como outras cidades petroleiras, tem fluxos de forte atração de população em conjunturas econômicas específicas. Isto provoca um déficit crônico de moradias em uma região de clima rigoroso. O monte Chenque dividia historicamente "o povoado" da zona petroleira. Próximo ao centro, sobre o Chenque, expandiram-se bairros populares. O sul, por sua vez, teve uma expansão populacional com um tipo de urbanização acelerada, caracterizada por surgir a partir de assentamentos populacionais. 
O município concentra a possibilidade de distribuir terras, mas esse processo é extremamente lento. A distribuição realiza-se a conta-gotas e muitas vezes se associa a acordos com os sindicatos. Assim, na trama central da cidade, dentro dos bairros, existem outros bairros que são praticamente quarteirões ou poucos quarteirões constituídos por moradias outorgadas a certos sindicatos. A isto se soma o fato de que ao redor das jazidas petrolíferas e do restante de empresas, como Ferrocarriles del Estado, Gas del Estado e outras de caráter privado, geraram-se bairros operários. Nesse sentido, considerando suas dimensões, Comodoro tem uma quantidade expressiva de bairros (cerca de 50), o que implica uma alta segmentação do espaço urbano.

Segundo as normas municipais, a concessão de terras prevê um ordenamento de categorias quanto às prioridades de acesso à moradia. De acordo com o decreto municipal no 5907-96 (artigo 34), estipula-se a concessão de terras de acordo com uma pontuação obtida, considerando-se dados como o de o receptor ser cidadão argentino ou não, natural da cidade, a antiguidade comprovada de sua residência na cidade e a quantidade de filhos, entre outros itens. O caráter normativo dessas prioridades articula-se com a legitimidade de categorizações e hierarquais. O fato de ter nascido na cidade e ser argentino conferir prioridades nada tem de natural. Menos ainda que isto esteja especificado em uma norma municipal.

Por outro lado, os conflitos pelos espaços habitáveis, inclusive pela ocupação de praças ou espaços comuns, foram o contexto em que surgiu outra categoria social muito utilizada: a dos assim chamados "filhos do bairro". Esta categoria significa que os que são filhos em segunda ou terceira geração das famílias fundadoras do bairro deveriam ter ou têm o privilégio de acesso a terra e à moradia.

Em termos mais gerais, o panorama está constituído por uma população com níveis de renda superiores à média do país, mas com um déficit crônico de moradias. Isto implica que pessoas com salários altos não têm onde morar, o que gera ocupações periódicas de terras. Estas ocupações, ao contrário das que ocorrem em Buenos Aires, não são especialmente protagonizadas por desempregados ou por pessoas abaixo da linha da pobreza, mas por trabalhadores que têm veículos caros e capacidade econômica de construção.

Um assentamento de poucos meses apresenta geralmente uma quadrícula que remete ao planejamento coletivo, a construções diversas, algumas das quais com bom material, diversos veículos de alto padrão e várias bandeiras argentinas como resposta à frequente acusação de que os ocupantes são estrangeiros. O poder aquisitivo indica que o problema não é tanto a construção, mas o acesso a terra em si. 
As ocupações de terra geram conflitos sociais e políticos amplos, nos quais os estereótipos e os estigmas fluem através dos discursos e dos meios de comunicação. A cada tomada, surgem vozes que reclamam um maior controle migratório, estabelecendo uma filiação entre as modalidades de assentamento de chilenos, bolivianos, paraguaios e imigrantes do interior do país. Todos eles são culpados de levar adiante "ocupações ilegais" e de serem portadores de modalidades delituosas. As soluções, tal como expresso por Carlos em um jornal local, são imaginadas deste modo: "primeira medida, repressão para os usurpadores como em Buenos Aires; segunda, casa para os comodorenses, depois para os do interior e, se houver lugar, para os estrangeiros (não se deveria nem deixá-los entrar)". Uma extensão desta perspectiva nos foi indicada por uma vizinha do bairro Mosconi, quando nos disse que "deveriam fechar a cidade". Para "parar a invasão", surge a imagem das cidades medievais com muralhas.

\section{Categorias e sentidos}

Até meados do século $\mathrm{XX}$, ser ypefiano implicava uma série de privilégios em relação ao resto da população local: acesso à moradia, atenção sanitária, compras com desconto no supermercado, locais destinados a férias em centros turísticos do país, entre outros aspectos. Neste sentido, os ypefianos foram configurando em Comodoro Rivadavia um setor que teve possibilidades de mobilidade social ascendente intergeracional. Desde as primeiras décadas distinguiram-se das camadas mais empobrecidas da população. Essas diferenciações no que diz respeito "ao povo" influíram na atitude indiferente de vários setores da sociedade comodorense no contexto da privatização da YPF.

Atualmente, aqueles que se encontram ligados à ex-empresa estatal, referem-se à sua história com orgulho e também com distinção diante de quem não faz parte do passado ypefiano. Um ypefiano que mora em Barrio Mosconi, que integra atualmente o grupo de docentes da "Escola de Petróleo" que forma técnicos, nos disse que tinha com a YPF

um vínculo para toda a vida, lar ypefiano, pai ypefiano, nascido no hospital da YPF, irmãos também, filhos também. Meu pai morreu no mesmo hospital da YPF, ou seja, há uma relação de toda a vida com a YPF... Ypefiano total. Os primeiros pensamentos de menino estão relacionados com o que era a YPF, com o transporte da YPF, até com o sorveteiro que chegava aos sábados quando eu vivia em Caleta Córdoba, um acampamento da YPF, todo mundo o esperava. 
Se queríamos ir ao cinema, também aos sábados, a única coisa que tínhamos que fazer era ir até o cinema. Isto também abrangia outras atividades sociais, podíamos ir ao colégio sendo da YPF. As mulheres faziam compras pela YPF. A YPF tinha fornecedores dos quais as pessoas compravam a preço de custo, e não se pagava o frete, a mercadoria vinha em barcos. Era tudo YPF...

Tirando o fato de que estas imagens podem estar carregadas de nostalgia, ajudando assim a relegar alguns conflitos, não há dúvida de que a privatização implicou uma grande transformação no início dos anos 90. Foi estudado como esse processo produziu efeitos sociais devastadores em muitas cidades petroleiras (Svampa \& Pereyra 2003). Foi nelas que surgiram os primeiros bloqueios de estradas realizados por trabalhadores desempregados, como em Tartagal e Plaza Huincul, em torno de 1996 - aqueles que depois seriam chamados de "piqueteiros". Mas não houve um processo similar em Comodoro Rivadavia. Por quê? Mesmo que seja arriscado estabelecer uma causa, o fato de que Comodoro não possa ser considerada uma company town, que tenha tido outras atividades produtivas e que isto seja parte do imaginário local certamente teve relevância. Neste contexto, neste lugar, "petroleiro" tem um significado diferente.

A vida econômica de Comodoro depende fundamentalmente do valor do petróleo. Quando da privatização da YPF no início da década de 90, surgiram alguns projetos econômicos que puderam substituir a centralidade da exploração petrolífera. Mas quase todos eles, até agora, acabaram falindo. Um novo ciclo de expansão da exploração petrolífera entre os anos de 2004 e 2008, e os esforços atuais de prolongar a assim chamada "paz social" por parte do sindicalismo petroleiro, têm feito com que ainda se sustente um mercado de trabalho estável e com salários superiores à média do resto dos trabalhadores da Argentina.

Os salários do pessoal petroleiro não qualificado estão entre os 8 e os 15 mil pesos mensais (entre 2 mil e 4 mil dólares). Os salários do pessoal qualificado, geralmente com estudos secundários completos ou mais, estão entre os 10 e um pouco mais de 20 mil pesos mensais (até 6 mil dólares). Que a vida patagônica seja mais cara que a das cidades dos pampas, é um dado da realidade. Aqui, este dado não tem maior interesse, porque estes custos são iguais para todos os habitantes de Comodoro. Se um professor ganha em torno de 500 dólares, um cargo de direção de escola pública não supera os 1.000. O certo é que entre os 12 e 15 mil empregados do petróleo (segundo dados dos sindicatos), o nível de renda está muito acima do resto dos trabalhadores e profissionais de Comodoro. Mas - e este é o ponto sobre o qual este artigo trabalha - este alto nível de renda relativo não corresponde ao prestígio social dos petroleiros. 
Em Comodoro há um desajuste entre a estrutura de renda e a estrutura de prestígio, entre nível econômico e hierarquia simbólica. Entre os que participam dos setores simbolicamente altos, podem estar criadores de gado ou grandes comerciantes, mas também ypefianos ou descendentes de ypefianos que já não trabalham no petróleo, mas que são profissionais, advogados, cinesiólogos etc.

Algo semelhante ao que ocorria em épocas passadas entre os ypefianos que eram reconhecidos e estigmatizados pelos não ypefianos, acontece atualmente em relação aos não petroleiros, que podem invejar o nível de renda dos petroleiros, mas dificilmente invejam seu trabalho ou seu estilo de vida. Em relação aos ypefianos, geravam-se antigamente, por parte dos não ypefianos, determinadas representações que davam conta de algumas suspeitas pelos "privilégios" de se pertencer à empresa petrolífera estatal. Essas percepções certamente exerceram influência no período de privatização da empresa YPF, visto o escasso apoio que receberam aqueles que realizaram manifestações contra as políticas neoliberais.

Mas os estereótipos e os estigmas que existem em torno do trabalhador petroleiro atual não são de modo algum comparáveis aos que predominavam em relação aos ypefianos. Particularmente, porque não se pode associar a renda petroleira a assistencialismo do Estado ou a políticas de bem-estar da empresa pública que estabelecia fronteiras com o resto dos habitantes da cidade. Os questionamentos a este salário por não petroleiros são contestados aludindo-se ao sacrifício e ao risco que implica a vida na boca do poço. Por sua vez, os trabalhadores de outras profissões comentam que não é maior o sacrifício que eles realizam para sustentar seu emprego.

Por outro lado, os petroleiros são objeto de questionamentos permanentes, de gozações sobre seu estilo de vida, sobre o que consomem, sobre seu modo de falar e sobre sua (in)cultura. Os que possuem cargos hierárquicos no mundo do trabalho petroleiro não se reconhecem como petroleiros. É frequente que se refiram aos petroleiros como pessoas ignorantes, de escassa instrução escolar, o que explicaria os tipos de valores e hábitos de consumo que possuem. Um técnico de uma empresa operadora comentou:

como todas as coisas, a falta de educação te faz ter interesses diferentes; lamentavelmente, sem precisar ir mais longe, você vê carros e caminhonetes zero km em casebres caindo aos pedaços, ou TVs de 42" LCD molhadas por goteiras. Tudo isso é uma questão, mas para mim tudo passa pela educação. Não se esqueça também que há pessoas que passaram muita necessidade a vida toda e que, quando se veem com um salário que lhes permite acesso a outras coisas, se perdem... 
"Perder-se" pode significar o consumo de drogas, acabar com o casamento, entre outras práticas que recebem a condenação moral tanto dos trabalhadores hierárquicos do petróleo quanto de outros setores sociais. Os homens não petroleiros mencionam não invejar nada dos petroleiros, porque sua forma de ser e de administrar o dinheiro não corresponde a seus próprios valores e desejos. No plano do consumo, afirma-se que eles têm "TVs de plasma sobre chão de terra" ou automóveis caros sem uma casa própria.

Outra das afirmações correntes é que suas mulheres os traem. É necessário entender, nesse sentido, que os petroleiros habitualmente passam 12 ou mais horas fora de casa. Mas, como muitos locais de trabalho se encontram a distâncias maiores, existem diversos regimes pelos quais eles podem passar 10 dias seguidos fora de casa em troca de cinco dias livres, 14 dias sem voltar contra sete dias liberados, e outros acertos do tipo.

Juan, um trabalhador petroleiro hierárquico, nos disse que

o petroleiro trabalha o dia todo, chega cansado, não quer sair, sua mulher tem muita grana para gastar, não trabalha, gasta tudo porque está "aborrecida"... então, daí surgem os problemas, porque elas já têm uma história com algum azarador que tem outro tipo de trabalho ou simplesmente não trabalha, que começa a se aproximar porque ela está sozinha... então, se armam umas ofensas bárbaras. Ele, por sua vez, faz o mesmo, se separam e bom, quanto dura depois a próxima relação? Dois anos até que se cansam dessa carne nova. Te conto porque eu próprio estou no processo de divorciar-me.

Neste sentido, apesar de não se sentir incluído na categoría petroleiros, Juan compartilha o ritmo de trabalho no petróleo que em certa medida considera "alienante".

O alto nível de renda é questionado porque aqueles que recebem o dinheiro não sabem gastá-lo adequadamente, porque o gastam em produtos da moda em vez de poupar. Além disso, muitos falam de uma sensação de certa prepotência: às vezes dos petroleiros, às vezes de suas esposas, às vezes de seus filhos. Alguém nos falou "de sua raça".

Uma professora do Chaco, para quem a "opulência" econômica gera indivíduos despreocupados e pouco cuidadosos com seus recursos, dizia que "trabalhando no petróleo é como se tivessem segurança econômica, então não importa se você vai mal na escola, se esbanja as coisas. Sempre chamo a atenção dos meninos para isso". Um jovem encarregado da coleta de lixo na empresa local também mencionava o risco de seu trabalho, ligado à violência nos bairros da periferia da cidade. Sobre seu salário nos disse que 
depende das horas extras, é raro que não faças e o máximo é \$5.000. Se não tivesse feito horas extras, este mês teria $\$ 4.000$. Se te endividas, queres te matar. Eles roubam: os petroleiros. E a culpa é deles, eles bancam os esnobes no supermercado. Dá para ver! Mas estão endividados até a raiz dos cabelos!

Isto se relaciona a várias histórias que indicam teorias nativas não petroleiras sobre o desajuste renda/prestígio que afirmam a suposta falta de capacidade de "gastar bem" o dinheiro dos petroleiros. É sobre as práticas de gasto que se multiplicam os questionamentos: por que gastam muito e poupam pouco, por que não investem, por que continuam vivendo como antes, por que quando vão comprar no centro da cidade agem de maneira prepotente? - e assim sucessivamente. Este tipo de discurso se irradia em momentos de crise tal como a vivida em fevereiro de 2009, quando ocorreu uma recessão na exploração petrolífera com a baixa do preço do cru em nível internacional. Os leitores de um jornal local disseram que esta situação deveria "diminuir a soberba petroleira". Uma mulher sugeria que os petroleiros "comecem a vender as TVs de plasma, os quadriciclos e os 4x4 para comprar arroz e macarrão". Nos setores de nível educativo médio alto, a capacidade de consumo dos petroleiros gera um grande ressentimento que, por sua vez, constitui uma barreira de contenção que dificulta a extrapolação do nível de renda para o nível de prestígio.

\section{Três formas de tensão}

O desajuste entre renda e prestígio gera tensões diversas e é onipresente na vida urbana. Em vez de assinalar as acusações e as respostas de uns e outros, percebemos que se desenvolve uma trama em que petroleiros, suas esposas e seus filhos se encontram complexamente enredados.

Por um lado, os petroleiros sofrem de modo evidente em seu corpo e em sua subjetividade condições de trabalho muito específicas, caracterizadas pela ausência de casa, pela vida em acampamentos, pelo frio da Meseta e pelo risco dos trabalhos. Constantemente, nos falam de tudo isso. O argumento que usam contra os que afirmam que ganham muito é que eles, com seu salário e consumo, sustentam a vida econômica da cidade, inclusive daqueles que os criticam. Além disso, nos dizem que quando lutam por postos de trabalho e para aumentar seus salários, buscam reduzir os grandes lucros das empresas petroleiras. É algo que nos contaram em papos nos bares, nos ginásios que frequentam e nas viagens de dia à Meseta: parece-lhes correto ganhar mais também porque com isso as empresas ganhariam menos. 
Agora, é certo que, mais que argumentar, os petroleiros fazem. Há vários indícios de que para a maioria deles não é fácil "desconectar-se" dessa dinâmica e construir uma vida local no tempo livre de que dispõem. Ao invés disto, parecem devotar-se a uma construção de espaços e símbolos de masculinidade. Nesse sentido, constroem um universo simbólico masculino no qual os signos de prestígio são os automóveis, os eletrodomésticos e as mulheres às quais têm acesso. São justamente estes símbolos que são desprestigiados pelos não petroleiros.

A estes trabalhadores resta pouco tempo livre para desfrutarem com suas famílias. Então, privilegiam compartilhar o resto do dia com seus companheiros de "equipe", sair de noite e buscar "excessos" que lhes permitam escapar da rotina. Uma das maiores atrações é o gosto por turbinar automóveis, nos quais podem investir valores que duplicam o preço de compra do veículo. "Turbinar" um carro implica personalizá-lo, dar-lhe cores, poltronas, volantes e outras características que os tornem completamente peculiares. ${ }^{3}$ Esses carros turbinados são para serem expostos em eventos especiais e usados em momentos particulares, deixando outro automóvel para a vida cotidiana.

De modo similar a como personalizam carros, criou-se uma ideia imaginosa em relação às suas mulheres. As esposas de petroleiros são muitas vezes chamadas de "as gordas", como categoria depreciativa. A ideia de "turbinar as mulheres" pode ser compreendida como uma resposta a esta estigmatização. Esta expressão, às vezes, é capaz de significar mudanças de roupas; em outros casos, operações estéticas; e em vários outros, aceder aos serviços vips da prostituição sempre associada ao mundo do petróleo.

Nos termos de Rubin Gayle, estamos diante de práticas que pretendem manter as "mulheres no seu lugar" (Gayle 1975:7), mas que se deparam com a oposição de mulheres que não aceitam de maneira alguma a submissão doméstica que uma boa renda econômica implica. As esposas dos petroleiros, em geral, não trabalham por causa da alta renda familiar. Isto se relaciona também ao fato de que a maioria dos petroleiros tem família relativamente numerosa, o que leva as mães, então, a se dedicarem às tarefas do lar. Mas diferentemente da mãe modelo das versões clássicas da desigualdade de gênero, associada ao elogio da submissão e da ausência no espaço público, os NYC de Comodoro desprezam as mulheres de petroleiros por sua "ignorância" e por outros aspectos culturais de sua "classe" (que não mudaria pelo nível de renda), seu modo de comportar-se na sociedade e, especialmente, nos âmbitos do consumo e do lazer, ou seja, por sua presença contundente no espaço público. Mas, sobretudo, pelas compras abundantes no supermercado e nas lojas de eletrodomésticos, e também por uma atitude que muitas vezes é considerada 
arrogante pelos empregados do comércio. Percorrer estes negócios, particularmente nos dias que antecedem grandes festividades, permite observar um formigueiro repleto de consumidores no qual o entusiasmo e a felicidade destas mulheres são decodificados pelos demais como "arrogância".

Também perturba a sua presença em lugares inesperados para outros participantes, como os cassinos da cidade. Um trabalhador petroleiro hierárquico referiu-se às esposas dos petroleiros como "mulheres chatas" que tiram proveito do salário de seus maridos: "Comigo ocorre que às vezes vamos jantar com os gerentes e os supervisores e eles gostam de ir ao cassino. Quanto chegamos lá, quem encontramos? As mulheres dos petroleiros da empresa. Não têm respeito nem pela pessoa que ganha o dinheiro!!". Ou seja, as mulheres dos petroleiros se reúnem e aproveitam para ir juntas a lugares que antes consideravam inacessíveis. Não é difícil entender o misto de alegria e excitação que atravessar estas fronteiras provoca nelas. Mas do ponto de vista dos gerentes e dos petroleiros hierárquicos, estes espaços estavam reservados para sua próprias classes. Compartilhá-lhos com outra classe e outro sexo é percebido como algo dramático e desrespeitoso. É o fim do espaço próprio, da hierarquia.

O capital simbólico potencial que poderia eventualmente emanar desta capacidade de consumo - dificilmente questionável do ponto de vista da economia moral da obtenção dos recursos - é cotidianamente solapado. Em vez disto, aponta-se contra o capital moral (Wilkis 2010) com afirmações contra as práticas econômicas de consumo que, por sua vez, são basicamente feminilizadas e atribuídas "às gordas". "As gordas" tanto se refere aos petroleiros quanto não se refere, e é desta ambivalência que o termo parece extrair seu potencial corrosivo e legitimador de desigualdades categoriais. Não fala dos petroleiros, já que estes homens realmente se esforçam para ganhar suas altas rendas em trabalhos que muito poucos daqueles que estão em posição de poder e os invejam aceitariam realizar. Mas o fato de que "as gordas" gastem este dinheiro expressa as escolhas "erradas" desses rapazes e homens ou, em visões mais resignadas, seu gostos horríveis e irreversíveis.

Para os trabalhadores hierárquicos do petróleo, apesar de os petroleiros aparentarem machismo e "esperteza" obtida na vida noturna, acabam sendo "vítimas" de mulheres "caça petroleiros". Então, formam casais com mulheres que já possuem filhos de uniões matrimoniais anteriores. Fabián, um técnico, nos disse:

vejo que muitas mulheres de petroleiros não trabalham e que, quando a mulher não trabalha, fica por aí e não se cuida, fica largada... E no casal, vejo que tenho companheiros por aí com mulheres que não lhes dão tudo que necessitam sexual- 
mente, não há novos estímulos, não geram um interesse. Tudo isso passa pelo cuidado pessoal, pela roupa que se usa, pela roupa íntima que motiva. E elas não se dedicam aos filhos, a cozinhar, a passar, algumas nem cozinham, nem preparam um bife para o marido, e tudo isso no casal. Os caras então saem por aí e vão a motéis vips com uma louca, ou enganam as mulheres diretamente com outra mulher...

Nesse sentido, os homens parecem ser vítimas da maldade feminina, operação que confere maior capacidade de dano ao estigma de gênero. Mas são suas próprias esposas que são questionadas por não saberem gastar o dinheiro que eles ganham, que são acusadas de infidelidade e, por diferentes modos de comportamento, mostrariam que, ainda que tenham dinheiro, não seriam aceitáveis aos olhos da sociedade estabelecida de Comodoro. Assim, a categoria petroleiro, que à primeira vista não parece ser objeto direto de estigmatização, encontra sua corrosão simbólica através de uma operação indireta.

Desta forma, esses homens esforçados que com enorme sacrifício obtêm rendas altas, são vistos com receio e invejados, mas se fala relativamente pouco disto, ou melhor, mencionam-se formas de estigmatização em relação aos trabalhadores, mas estas tendem a ser abertamente contestadas e discutidas. Em troca, quando o ressentimento gerado pelo fato de que classes supostamente mais baixas tenham rendas maiores se reconverte em desprezo de gênero, o estigma aparece como muito mais efetivo.

A maior parte dos petroleiros considera que são justamente as novas possibilidades abertas por suas rendas salariais, as novas práticas e os novos objetos de consumo que lhes conferem um prestígio que contesta a carga pejorativa que pode ter o apelido de petrolines* ou de negros petroleiros. As práticas de consumo e o modo de manifestá-las estariam dando mostras do "orgulho" que significa para os petroleiros a posse de um carro "turbinado" sem cano de descarga, elemento que para as classes médias e profissionais da cidade é algo "grotesco", tal como comentou recentemente um engenheiro universitário em um programa televisivo local, para quem os petroleiros são sinônimo de "trânsito violento" na cidade:

Essa bipolaridade... eles dizem que quando trabalham se sentem controlados e então sentem uma espécie de liberação quando param de trabalhar. Cuidam mais do veículo da empresa do que de seus carros, mais de seus companheiros de trabalho que de seus filhos.

* [N.T.] Termo original em espanhol. 
Os filhos de petroleiros são vistos como as vítimas do estilo de vida levado por seus pais. Para os agentes estatais que convivem com os problemas de crime, drogas e álcool entre os jovens, o problema reside nos pais "ausentes" que, em geral, não sabem como educar seus filhos. Uma profissional do Serviço Social de um bairro na zona sul de Comodoro nos disse que as famílias do bairro atravessam uma série de dificuldades porque "o problema é que passaram a ganhar muito e ninguém lhes ensinou a administrar nada". Nos Centros de Promoção do Bairro (CPB) foram implementadas as chamadas "escolas para pais", nas quais profissionais oferecem orientação sobre como conduzir a criação dos filhos quanto à imposição de limites e comportamentos. Os professores das escolas públicas comentam que têm que lidar com pais que consideram que dar um celular caro a seus filhos é suficiente para que eles se sintam estimulados a estudar. Uma das teorias nativas da desigualdade afirma que uma sociedade construída em parte com base na ausência dos pais homens em casa está fabricando novos problemas sociais. Afirma-se que esses pais que não sabem ou não podem colocar limites para seus filhos, que chegam cansados a uma casa em que sempre estão de visita ou de passagem, tentam dar-lhes "grana em lugar de afeto". Isto se traduziria nas condutas de seus filhos dentro e fora da escola, onde também o termo prepotência se faz presente. Enquanto os filhos parecem abordar suas próprias lutas por prestígio através dos mecanismos instituídos pelos sapatos da moda ou pelos celulares novos, a sociedade insiste em condená-los pelas condições que lhes são ofererecidas em casa, por seu estilo de vida ou por suas formas de consumo. Os filhos, suas vivências, suas práticas escolares e urbanas requerem um estudo à parte. Aqui nos interessa destacar que estas "consequências da ausência do pai", articuladas com os medos mais globais que os jovens e suas práticas noturnas produzem, fazem retornar a Comodoro as questões da "anomia" como um dos principais legados do petróleo.

Estas três formas de tensão (a dos petroleiros, a de suas esposas e a de seus filhos) dão conta de (pelo menos) duas concepções completamente divergentes sobre a construção do prestígio e das hierarquias simbólicas. Seguramente, uma destas versões se encontra instituída e é a perspectiva hegemônica. É visível em algumas instituições escolares da cidade, na valorização dos bairros e na classificação do tipo de pessoa que é associada, obviamente, às categorias preferenciais para eleição do cônjuge. Diante destes signos, os petroleiros continuam claramente deslocados, já que não mudam de bairro nem de escola, nem têm acesso para casar-se com mulheres que integram os círculos mais exclusivos da sociedade comodorense: as moças NYC. Seguramente, os petroleiros e suas esposas vêm de trajetórias familiares muito heterogêneas: alguns de famílias de migrantes rurais patagônicos, de migrantes 
de províncias do norte, de países limítrofes, dos trabalhadores ypefianos de menor qualificação e de outros setores de trabalhadores. Não é impossível que tenham nascido e se criado em Comodoro, mas nos usos da elite o termo "nyc" tem fortes ressonâncias de classe e, neste sentido, os exclui.

Eles, suas esposas e seus filhos buscam outros signos de prestígio, estreitamente vinculados à sua capacidade de compra. O dinheiro permite "não serem domesticados", e constitui um poder para que possam continuar a ser diferentes e a não se adaptarem aos padrões "civilizatórios". ${ }^{4}$ Mas em Comodoro parece haver um "diálogo de surdos", no sentido de que as práticas de prestígio dos petroleiros são as mesmas escolhidas por outros setores para desprestigiá-los. Em termos de universos simbólicos, isto coloca a existência de uma cidade partida.

Ao colocar que se trata de uma cidade partida, com (pelo menos) dois grandes universos simbólicos que geram uma tensão e disputas em termos que tendem a ser decodificados de modo muito diferente por suas respectivas alteridades, não pretendemos reduzir os problemas de Comodoro a uma questão cultural. Os habitantes de Comodoro têm listas de situações "anômicas": filhos de petroleiros que carecem de limites, venda de drogas, altos índices de suicídio, situações de violência urbana, mulheres e homens infiéis, prostituição etc. A principal teoria nativa para explicar estas situações é a da ausência do pai em casa e as particularidades familiares que isto implica. Mais raramente menciona-se algo crucial: as condições extremas de trabalho no campo, nos poços, que é a causa evidente da fraca presença dos pais em casa. Outra teoria nativa, como em tantos lugares, refere-se à responsabilidade do Estado pelos graves déficits das políticas públicas, em particular quanto à educação.

Queremos assinalar que as condições de trabalho e os déficits de educação são extremamente relevantes, mas não dão conta de explicar outras dimensões simbólicas ligadas a elas. O caráter altamente segmentado e o predomínio de círculos segmentados da sociedade comodorense, perceptível na organização espacial da cidade e no mercado matrimonial, encontram-se imbricados em um sistema classificatório que insiste em uma cisão entre a sociedade estabelecida: os petroleiros e os recém-chegados. Há outros déficits de políticas públicas que alimentam esta situação, como a falta de intervenção nas condições de trabalho, a falta de espaços públicos na cidade, a hierarquização das instituições educativas e a ausência de reconhecimento da história dos trabalhadores petroleiros em uma cidade petroleira.

As tensões implicadas nesta cisão apontam para uma dinâmica em que a mútua incompreensão se conjuga à persistência das hierarquias simbólicas. 


\section{Sobre a legitimidade dos (des)ajustes}

A pergunta que nos interessa é em que situações sociais e contextos históricos as percepções, as vivências, os sentidos comuns e os argumentos de diferentes atores sociais a respeito das diferenças e das desigualdades entre as pessoas e os grupos tornam-se convergentes e articulados, em que grau e com que persistência. E também em que situações e contextos tornam-se divergentes, em que grau e com que consequências nos cenários públicos e na vida social.

As desigualdades têm legitimidades sociais específicas em diferentes setores sociais e contextos culturais. Estão sustentadas por sentidos comuns e modos de classificação muito diferentes em uma ou em outra região, em uma ou em outra classe social. Os argumentos, as crenças e os mitos que os setores hegemônicos produzem são muito variáveis em diferentes zonas ou em culturas locais para relações sociais formalmente equivalentes (empregador-empregado, homens-mulheres, migrante-nativo). Quer dizer, a vivência, a classificação e a significação de um tipo de posição "objetiva" na estrutura social não necessariamente coincidem em espaços culturais próximos. $O$ fato de que estas dimensões simbólicas sejam distintas vincula-se àquele de que as relações sociais formalmente equivalentes são efetivamente diferentes nos distintos países, nas zonas e nas províncias (ver Reygadas 2008).

Toda sociedade, como mostrado há muito tempo por Durkheim e Mauss (1996), produz inúmeras classificações. A mais fundamental delas se refere às divisões e aos agrupamentos da própria sociedade e das sociedades vizinhas, ou os "outros significativos". Uma sociedade tem assim uma caixa de ferramentas identitária, um conjunto de classificadores disponíveis com os quais seus membros podem identificar-se a si mesmos e identificar os outros. As classificações são mais compartilhadas que os sentidos destas classificações (Grimson 2011). Assim, "petroleiro", "patagônico" ou "nyc" (nascido e criado em Comodoro Rivadavia) pode adquirir sentidos negativos ou positivos para diferentes membros da sociedade e, tal como estabelecido pela investigação antropológica, os sentidos negativos podem desmembrar-se em diferentes tipos que vão desde o racismo, o classismo, o fundamentalismo cultural ou outros. Por isto, uma parte decisiva dos conflitos sociais é uma disputa sobre o sentido das categorias classificatórias.

Nesse processo de circulação social de categorias e classificações humanas, disputam-se sentidos, desigualdades e hierarquias (Tilly 2004). Estas disputas são factíveis, porque as categorias são compartilhadas, porque os significantes se somam a algum significado, ainda que não necessariamente os mesmos. "Petroleiro" pode significar trabalhador sacrificado, sindicalizado, 
que não sabe gastar o que ganha, inculto, bruto, corno ou pai ausente. Uma análise desta perspectiva permite construir uma cartografia das categorias identitárias e de disputas que acentuam significados contrastantes de um mesmo termo, disputas estas que são a arena em que se encontram perspectivas contrastantes sobre a estrutura social, seus estratos e setores, a valorização dos mesmos e suas legitimidades.

Trata-se de teorias nativas da desigualdade social que têm, pelo menos, duas dimensões. Por um lado, são teorias nativas sobre como é/são a estrutura social, a estratificação, as posições, os níveis. Neste plano, podem reconstruir-se perspectivas descritivas sobre a estrutura. Por outro lado, são teorias nativas sobre a legitimidade ou a ilegitimidade dessa estruturação da sociedade, ou seja, valorações, concepções morais, e significados politicamente carregados sobre a justiça e a a injustiça da "realidade" descrita no plano anterior. Certamente esta distinção de planos é analítica e não nativa, mas esta diferenciação teórico-metodológica pode contribuir para o rigor da análise compreensiva.

\section{Desajustes assincrônicos?}

Agora, voltando à questão dos petroleiros, encontramos um caso cuja peculiaridade jaz no desajuste extremo entre o nível de renda e o nível de prestígio. Estes ajustes ou desajustes entre a estrutura social e as desigualdades de renda, por um lado, e as hierarquias simbólicas e as desigualdades de prestígio social, por outro, nos colocam questões cruciais sobre como se legitimam as desigualdades. Certamente conhecemos diversas sociedades nas quais há uma coincidência tal entre as hierarquias de renda e as hierarquias simbólicas - como no feudalismo clássico — que estimulam a que nos perguntemos sobre a causalidade, em termos de se os prestígios expressariam ou gerariam esses predomínios econômicos. Tanto na perspectiva da causalidade econômica como na da performatividade simbólica, assim como no racialismo mais clássico (Todorov 1991), as reconversões de capitais culturais e econômicos seriam constantes.

Diante de situações de claro desajuste entre níveis de renda e níveis de prestígio, pode-se convocar a categoria "tempo" para afirmar que a intensidade e a velocidade dos fluxos entre os tipos de capital são variáveis e assim se explicar uma falta contingente de superposição.

Gostaríamos de oferecer alguns exemplos simplificados. Se em uma sociedade organizada com base no parentesco há dote das noivas e há poligamia autorizada exclusivamente para o chefe, fica evidente que ele 
receberá maiores dotes que o resto dos homens de sua tribo. Se é chefe por este poder econômico ou se possui este capital por ser chefe, é uma discussão que pode ser ora interessante, ora viciada, mas que se desenvolve em um contexto de ajuste de ambas as estruturas.

Em uma aldeia feudal, em suas variantes clássicas e em suas versões latino-americanas, supõe-se que deve haver uma superposição das estratificações econômica e simbólica. A emergência da burguesia, neste sentido, colocava uma anomalia que efetivamente tendeu a resolver-se com o passar do tempo.

Mas, se agregamos uma certa complexidade a este quadro, encontraremos um forte desajuste na sociedade contemporânea, por exemplo, no caso do narcotráfico. As classes privilegiadas tradicionais, com alto nível educacional e prestígio social, encontram-se diante de um setor emergente que, apesar de não adquirir prestígio entre os setores hegemônicos, supera amplamente os níveis de renda tradicionais. Certamente, aqui aparecem várias complicações interpretativas. Por um lado, porque em sociedades complexas os circuitos de distribuição e legitimação do prestígio são variados e muitas vezes contraditórios: ser prestigiado nos meios de comunicação não assegura algo equivalente nos bairros mais pobres e, obviamente, viceversa. Por outro lado, o tema que nos interessa aqui é que há vários casos em que o desajuste não parece atribuível a uma "anomalia" temporal. Por mais que se assuma que as desigualdades e as hierarquias de qualquer tipo encontram-se tão sujeitas à historicidade como todo o social, a pergunta é se a não correspondência é um problema de transição à correspondência.

No caso do narcotráfico, emerge de maneira clara uma dimensão especificamente moral que afeta de modo direto a potencialidade de reconversão do capital econômico em simbólico: o questionamento à legitimidade moral da obtenção deste capital econômico. Este grupo possui um nível de renda muito alto, que lhe permite construir novos bairros ou instalar-se em bairros tradicionais, bem como frequentar as redes de clubes, associações, igrejas e escolas privadas das elites tradicionais. Ter o dinheiro para comprar uma casa no bairro da elite tradicional não implica ser aceito por ela. Os casos de rejeição destes grupos emergentes por setores das elites tradicionais, ou as divisões nas antigas elites em torno da aceitação ou não destes grupos, são de algum modo uma disputa sobre se eles são "gente como nós", se "são daqui" ou, por algum motivo, se nunca poderão ser pessoas com o mesmo capital simbólico que os membros das elites, por mais que os superem em capital econômico.

Recordemos com Elias e Scotson (2000) o caso de Newcomb. O conflito se produz entre os brancos mais empobrecidos e os negros com menores 
dificuldades econômicas. Nessa sociedade em que as correspondências históricas entre renda e prestígio estão ameaçadas, Elias mostra que o último dos monopólios dos estabelecidos em Newcomb é o acesso às mulheres do próprio grupo e sua interdição aos outsiders. A contrapartida disto em Comodoro poderia ser encontrada especialmente na estigmatização do tipo de mulher a que os petroleiros teriam acesso. Mulheres que já em sua denominação não cumpririam o estereótipo corporal, o paradigma próprio da estética atual: seriam gordas. Mulheres que não cumpririam o requisito de fidelidade. Mulheres que não saberiam administrar o que ganham, com esforço, seus maridos, sendo nisto também desleais.

\section{Desajustes persistentes}

São necessárias perspectivas não teleológicas sobre esta interrelação entre capital econômico e capital simbólico. No texto clássico de Elias, Established and outsiders (2000), há uma explicação política sobre a produção de prestígio. Os estabelecidos adquirem uma posição performativa quanto às classificações por sua coesão como grupo que, casuisticamente, deriva do seu tempo de residência na cidade. Elias propõe generalizar a questão política (descartando a econômica) vendo a coesão como uma dimensão crucial desta produção de poder. Nas diversas situações que menciona sobre relações do tipo estabelecidos/outsiders, existem casos em que o poder econômico, a nacionalidade, a raça, o gênero ou a religião poderiam ser os elementos legitimadores desta desigualdade. O movimento teórico de Elias consiste em repor a contingência da legitimação, mas sustentando que em qualquer dos casos se trata basicamente de um processo de "poder".

Pois bem, no caso de Winston Parva e em Newcomb, os que ocupam o lugar de estabelecidos ou têm o mesmo nível de renda ou um nível maior. Comodoro nos interpela a pensar sobre a desigualdade e suas dimensões com outros acentos. Ali, racializando as diferenças de classe, "os negros ganham mais". ${ }^{5}$ Sabemos que as desigualdades de renda são complexas: são desiguais os que têm rendas idênticas com níveis de qualificação muito distintos, ou os que têm rendas distintas adequadas a seus diferentes níveis de qualificação? A qualificação, o esforço, o sacrifício, o risco, as condições são meramente argumentos ex post para legitimar desigualdades de renda? Ou são fatores que podem ser reais e que impõem uma distinção de renda porque, se não fosse assim, ninguém quereria sacrificar-se, arriscar-se ou qualificar-se?

Colocado deste modo, não temos um problema novo para a filosofia política. O que é menos clássico, ainda que tenha tido importantes desenvol- 
vimentos recentes, é perguntar-se que critérios se aplicam em uma cidade, em um espaço cultural ou em uma província social para responder a estas perguntas. E que debates, tensões e conflitos sua aplicação gera. Que noções ou cosmovisões há neste espaço sobre quem são seus integrantes e sobre como devem articular-se as desigualdades ${ }^{6}$ de rendas e as desigualdades simbólicas. As ferramentas sociodemográficas permitem, pelo menos em espaços delimitados, reconstruir as relações complexas entre níveis de renda e hierarquias simbólicas. Isto implica no fato de que podemos tentar responder qual das visões ou das teorias nativas sobre como deveria ser esta relação entre diferentes hierarquias se impõe em um determinado momento, em uma estrutura da conjuntura. E como e por quem é disputada, enfrentada, aceita, incorporada e naturalizada.

Os casos de desajuste entre nível de renda e capital simbólico permitem que nos perguntemos de onde emana a legitimidade ou a ilegitimidade social de tais desigualdades econômicas. Já mencionamos, no caso de uma teoria nativa - das elites - , que se questiona o capital moral de alguns setores pela origem ilegal de seu capital econômico.

Como a heterogeneidade cultural existe e tem a ver com experiências históricas de mobilidade social ascendente, bem como com concepções nativas sobre quão imoral e ilegítima é a ilegalidade, não encontramos uma rejeição homogênea à convivência ou uma eventual incorporação de pessoas ou grupos com um capital moral escasso. As distintas ações tendentes à persistência ou à quebra do desajuste constituem intervenções nativas que têm implicações teóricas sobre se se trata de uma assincronia que tenderá a corrigir-se ou se se trata de uma autonomia dos capitais.

Os processos de escolarização e as alianças matrimonais podem constituir campos de exploração desses processos de incorporação, assim como das fontes da ilegitimidade eventual do capital econômico. Há casos por demais conhecidos de segregação de meninos e de famílias por questões raciais ou de nacionalidade para que nos detenhamos a analisálos. Mencionemos simplesmente os distintos exemplos na Argentina de questionamentos sobre meninos estrangeiros que tenham a honra de carregar a bandeira nacional em atos escolares, que é um questionamento à legitimidade da acumulação de prestígio pessoal, familiar e eventualmente étnico que este ato implica.

No caso de Comodoro Rivadavia, não estamos diante de uma situação plena de "terror étnico" (Segato 2007:51), mas talvez de um "pânico de classe", em que as classes médias e altas sentem ameaçados seus espaços de recreação, difusão e educação, anteriormente dotados de certa exclusividade hoje inexistente. Os efeitos do "último boom do petróleo", com a chegada 
de novos migrantes bolivianos, paraguaios e peruanos, entre outros grupos migratórios que complexificaram o mapa populacional comodorense, geraram uma espécie de "caos classificatório" em que os estabelecidos sentem nostalgia de épocas passadas em que a cidade era um "grande povoado".

Em muitos casos, o questionamento à legitimidade da eventual ascensão econômica de setores de imigrantes pode se encontrar ancorado na racialização das relações de classe. Mas a permeabilidade do politicamente correto nem sempre permite a emergência pública desta racialização, que se desloca para a linguagem da legalidade: o caráter de "sem papéis" ou de "sem documentos" surge como o novo sentido comum sobre a expropriação de direitos de setores inteiros da população, assim como em relação ao questionamento sobre a legitimidade de seu presumido capital simbólico. Este trabalho de solapamento do capital moral é amplamente bem-sucedido na medida em que coage os imigrantes estigmatizados a aceitarem níveis de renda e condições de trabalho piores que outros com igual qualificação. Além disso, e fundamentalmente, reserva-se para aqueles que podem progredir economicamente nestas condições extremamente difíceis a capacidade de erodir seu capital simbólico com base em uma suposta imoralidade constitutiva.

Daí o interesse do caso de Comodoro Rivadavia, que apresenta semelhanças e diferenças com o caso histórico de Winston Parva. Não há diferenças uniformes de origem racial, étnica ou nacional entre os profissionais e os comerciantes, de um lado, e os petroleiros, de outro. Não há questionamento à origem de seu capital econômico, não só porque se regem por acordos coletivos de trabalho legalmente instituídos, mas porque os setores com prestígio não aceitariam realizar o trabalho sacrificado dos petroleiros. Argumentos ad hoc que podem surgir episodicamente, vinculados à migração interna (em oposição aos NYC, os nascidos e criados na Patagônia) ou à discriminação racial, não conseguem instituir-se como argumentos consensuais que solapem massivamente o capital simbólico do grupo trabalhador.

A dupla dificuldade perceptível na vida social refere-se tanto aos obstáculos para desenvolver um argumento aceitável de segregação simbólica quanto à resistência profunda em aceitar uma correlação mecânica entre níveis de renda e hierarquias de prestígio. Os setores das classes médias comodorenses gostariam que o desajuste não resultasse de uma assincronia passageira, mas que fosse permanente, ao menos no plano simbólico, algo para o qual intervêm muito ativamente. Não gostariam de abrir mão do prestígio e do poder.

A racialização intermitente, mas recorrente da classe operária funciona assim: em um país "sem negros", mas no qual os pobres são historicamente 
"negros" ou "cabecinhas negras", os petroleiros podem ser considerados "a negrada". Ter dinheiro não faz com que deixem de ser pobres no sentido étnico-racial do termo. Aqui aparece um motivo da persistência do desajuste: a sociedade com castas deve sobreviver às transformações econômicas.

Mas a raça não fornece um argumento consensual em Comodoro. É muito mais uma classificação implícita e privada que não pode emergir no espaço e no debate público. O paradoxo é que na medida em que argumentos vinculados a variáveis sociológicas (como raça, nacionalidade, lugar de nascimento, tempo de residência) não são verossímeis para instituir um consenso, parecem crescer outros processos argumentativos vinculados à esfera privada e íntima. Estes tipos de argumento também estão presentes muitas vezes em outros casos, quando se alude ao baixo capital simbólico de um grupo em função de suas práticas alimentícias ("comem coisas horripilantes"), de suas formas comunicativas ("os bolivianos são muito fechados, sempre mantêm as janelas abaixadas"), ou diversas outras. Agora, quando os argumentos simples com implicações complexas ficam barrados em suas tentativas de emergir, persiste um acúmulo de argumentos sobre o estilo de vida do grupo em questão. Estilo de vida que, por suas formas de cuidado com os filhos, por suas supostas infidelidades ou práticas homossexuais e por suas formas de uso do dinheiro ("não sabem poupar e compram TVs de plasma"), solapa cotidianamente qualquer pretensão de acumulação de capital moral e simbólico.

O caso de Comodoro parece mostrar não só esta modalidade abertamente desenvolvida. Também mostra que esta desigualdade de classe vivida com profundo incômodo por setores de elite, que não pode ser dirigida basicamente à origem racial, étnica ou nacional, se desloca, então, para uma questão de gênero. Em grande medida, os petroleiros têm seu capital moral solapado pelas práticas de consumo e pelas supostas infidelidades das "gordas". Ou por formarem casais com mulheres dominicanas (associadas ao imaginário da prostituição), ou com outras denominadas de "caça petroleiros", que dificilmente são aceitas socialmente. $\mathrm{O}$ argumento de gênero condensa e engloba todos os argumentos restantes.

Nossa hipótese teórica é a de que a tensão conceitual entre a autonomia das esferas de hierarquização e os desajustes assincrônicos se resolve em favor da primeira. Os desajustes poderiam ser assincrônicos ou persistentes, dependendo fundamentalmente das ações cotidianas e da instituição consensual ou não das hierarquias simbólicas e da legitimidade do capital moral. Não há nada no capital econômico que estabeleça teleologicamente que o desajuste deva resolver-se na esfera simbólica. No longo prazo, poderá ou não se produzir um ajuste. Isto dependeria, se 
não nos enganamos, especificamente das ações dos sujeitos envolvidos, de suas disputas pelos significados dos termos identitários, ou seja, dependeria basicamente de processos políticos circunscritos à configuração sócio-histórica considerada.

No caso de Comodoro Rivadavia, apesar dos antigos ypefianos de décadas passadas e dos trabalhadores petroleiros atuais compartilharem níveis semelhantes de escolarização, a inexistência de categorias prévias no caso dos primeiros, somada à presença de políticas de bem-estar emanadas da empresa estatal, deu origem a uma mobilidade categorial classificatória vinculada a certa mobilidade social ascendente. Em troca, a situação dos atuais petroleiros estaria mostrando uma persistência das desigualdades iniciais apesar das altas rendas salariais.

Comodoro Rivadavia é um caso extremo que, justamente por isto, revela que uma distribuição econômica equitativa é uma condição necessária mas não suficiente para uma redução multidimensional da desigualdade. É uma condição necessária porque, na medida em que exista uma sincronia entre a desigualdade de renda e a hierarquia de prestígio, é gerada uma forte estabilidade que aponta para a persistência. Mas em tensão com as teorias economicistas não é uma condição suficiente, porque os outsiders ou os setores subalternos deverão intervir em uma disputa sobre os capitais simbólicos e seus processos de legitimação. Uma melhor distribuição contribui, mas de nenhum modo garante por si mesma, nem a existência dessa disputa, ou muito menos seu êxito.

Recebido em 20 de abril de 2011

Aprovado em 02 de setembro de 2011

Tradução de Maria Barroso Hoffmann

Alejandro Grimson é professor da UNSAM e pesquisador do CONICET. E-mail: <agrimson@fibertel.com.ar>

Brigida Baeza é professora da UNPSJB e pesquisadora do CONICET. E-mail: <brigida_baeza@hotmail.com> 


\section{Notas}

* Desejamos agradecer pelos comentários a versões anteriores deste trabalho a Federico Neiburg, Luiz Fernando Diaz Duarte, Máximo Badaró, Mariana Heredia, Karina Bidaseca, Fernando Rabossi, Pablo Semán e outros membros do Núcleo de Pesquisas em Cultura e Economia (Museu Nacional UFRJ), do Grupo de Trabalho de Cultura e Poder do CLACSO, e do Programa de Legitimidades da Desigualdade (IDAES-UNSAM), com apoio do Projeto PICT-ANPCYT e PIP CONICET.

${ }^{1}$ Uma situação semelhante à apresentada aqui é analisada por Diana Nogueira de Oliveira para o caso dos "emergentes", um grupo social em ascensão econômica na Barra da Tijuca (Brasil), ao qual faltam reconhecimento e prestígio por parte da elite dominante do lugar (Lima 2007).

${ }^{2} \mathrm{O}$ censo nacional de 2010 registrou 192.000 pessoas. Como em outros lugares do país, há atores locais que afirmam que houve quarteirões inteiros que não foram recenseados. Outros, por sua vez, assinalam que se trata de um dado realista, já que está de acordo com os fornecimentos de eletricidade existentes nas casas.

${ }^{3}$ O termo "turbinar" ("tunear" em espanhol) obviamente é uma hispanicização do inglês. Só que o "tuning" (sintonizar) nos Estados Unidos refere-se, em relação a carros, a trocas e a ajustes feitos especificamente no motor. As trocas realizadas na Argentina sob o termo "turbinar" são similares às realizadas nos Estados Unidos sob o termo "customizar". Ainda que um dicionário possa traduzi-lo como "personalizar" (modo pelo qual se traduz "tuning" em Comodoro), o termo em inglês vem de clientes que assinalam uma diferença significativa em relação às suas traduções em espanhol (a comparação com os Estados Unidos surgiu de uma conversa com Renato Rosaldo).

${ }^{4}$ Fernando Rabossi, quando este texto foi debatido no NUCEC, sugeriu esta última ideia, perguntando-se se o dinheiro não lhes permitiria, usando um termo popular, "continuar sendo verdadeiramente negros".

${ }^{5} \mathrm{Na}$ Argentina, o termo "negro" é frequentemente usado para fazer referência aos trabalhadores ou a setores populares sem nenhuma ascendência africana. Simplesmente sua condição social os "enegrece".. 


\section{Referências bibliográficas}

BAEZA, Brígida. 2006. "Chilenos y bolivianos en Comodoro Rivadavia (Chubut)". In: A. Grimson \& E. Jelin (orgs.), Migraciones regionales hacia la Argentina. Diferencia, desigualdad y derechos. Buenos Aires: Prometeo. pp. 353-378.

BARROS, Sebastián. 2009. "Peronismo y politización. Identidades políticas en la emergencia del peronismo en la Patagonia Central". Estudios, 22:21-48.

BUDIÑO, Lino Marcos. 1971. Comodoro Rivadavia, "sociedad enferma". Buenos Aires: Talleres Gráficos Gáramont.

CARRIZO, Gabriel. 2007. "De obreros, pelotas y botines. El processo de popularización del fútbol en Comodoro Rivadavia en las primeras décadas del s. XX". In: B. Baeza; E. Crespo \& G. Carrizo (orgs.), Comodoro Rivadavia a través del siglo XX. Nuevas miradas, nuevos actores, nuevas problemáticas. Buenos Aires: Talleres de Gráfica MPS S.R.L. pp. 211-239.

2010. Sindicatos libres, Judas del proletariado argentino. Populismo y sindicalismo en Comodoro Rivadavia durante el primer peronismo. Tese de doutorado, Centro de Estudios Avanzados, Universidad Nacional de Córdoba, Argentina

CRESPO, Edda. 2001. "De Germinal a Florentino Ameghino. Memoria, política y asociacionismo en Comodoro Rivadavia (1919-1923)". Entrepasados, X(20/21):101-113. . 2009. "Más allá del ritual de belleza. Las reinas del petróleo en sus imágenes y palabras". In: M. González \& E. Crespo (eds.), Mujeres en palabras de otras mujeres. Rawson: Grupo Interdisciplinario de Estudios de Género (UNPSJB). pp. 87-93.
DE BOER, Miguel Ángel. 1993. Desarraigo y depresión en Comodoro Rivadavia (y otros textos). Comodoro Rivadavia: Ediciones Crónica 170.

DURKHEIM, Émile y MAUSS, Marcel. 1996. "Sobre algunas formas primitivas de clasificación. Contribución al estudio de las representaciones colectivas". In: É. Durkheim, Clasificaciones primitivas y otros ensayos de sociología positiva. Barcelona: Ariel.

ELIAS, Norbert \& SCOTSON, John. 2000. Os estabelecidos e os outsiders. Rio de Janeiro: Jorge Zahar Editor Ltda.

GAYLE, Rubin. 1975. "Tráfico de mujeres: notas para una economía política del sexo". Revista Nueva Antropología, VIII(30):94-145.

GRIMSON, Alejandro. 2011. Los límites de la cultura. Crítica de las teorías de la identidad. Buenos Aires: Editorial Siglo XXI.

LIMA, Diana Nogueira de Oliveira. 2007. "Ethos 'emergente': as pessoas, as palavras e as coisas". Horizontes Antropológicos, 13(28):175-202. Disponível em: http://www.scielo.br/scielo. php? script $=$ sci_arttext $\&$ pid $=$ S0104 $71832007000200008 \& \operatorname{lng}=\mathrm{en} \& \mathrm{nrm}=$ iso >. Acessado em: 01/09/2011.

MARMORA, Lelio. 1968. Migración al sur, argentinos y chilenos en Comodoro Rivadavia. Buenos Aires: Ediciones Libera.

MARQUES, Daniel \& PALMA GODOY, Mario. 1993. Comodoro Rivadavia en tiempos de cambio. Una propuesta para la revalorización de nuestras identidades culturales. Comodoro Rivadavia: Ediciones Proyección Patagónica. . 1995. Distinguir y comprender. Comodoro Rivadavia: Ed. Proyección Patagónica. 
MORENO, Carlos Alberto. 1985. Patagonia punto crítico. Comodoro Rivadavia: Fondo Editorial de Canal 9 de Comodoro Rivadavia.

REYGADAS, Luis. 2008. La apropiación. Destejiendo las redes de la desigualdad. Alicia Ziccardi. México: Anthropos/UAM-Iztapalapa.

SEGATO, Rita Laura. 2007. La nación y sus otros. Raza, etnicidad y diversidad religiosa en tiempos de políticas de la identidad. Buenos Aires: Prometeo libros.

SVAMPA, Maristella \& PEREYRA, Sebastián. 2003. Entre la ruta y el barrio. La experiencia de las organizaciones piqueteras, Buenos Aires: Ed. Biblos.

TILLY, Charles. 2004. La desigualdad persistente. Buenos Aires: Manantial.

TODOROV, Tveztan. 1991. Nosotros y los otros. México: Siglo XXI.

TORRES, Susana. 1995. Two oil company-towns in Patagonia: european inmigrants, class and ethnicity, 19071933. Tese de doutorado, Rutgers University. . 2001. "La inmigración chilena en Comodoro Rivadavia". Revista de Estudios Trasandinos, 5:39-98.

WILKIS, Ariel. 2010. "Capital moral et pratiques économiques dans la vie sociale des classes populaires de la banlieue de Buenos Aires". Tesis doctoral de la Ecole de Hautes Etudes en Sciences Sociales (EHESS) y la Universidad de Buenos Aires (UBA), mimeo. 350 pp 
Resumo

O artigo analisa uma situação em que trabalhadores fortemente estigmatizados têm níveis de renda mais altos do que aqueles que os estigmatizam. Desta forma, afirmamos que na cidade patagônica de Comodoro Rivadavia há um desajuste entre hierarquias simbólicas e nível econômico. Interessados nas desigualdades sociais e nos modos pelos quais elas se legitimam culturalmente, trabalhamos em conjunto com um antropólogo residente em Buenos Aires e uma antropóloga local. Um caso excepcional como o de Comodoro nos revela aspectos dos casos supostamente "normais", nos quais as hierarquias de prestígio são mais ou menos proporcionais aos níveis de renda. Em segundo lugar, ele nos permite perceber que os casos em que esta correlação não se verifica são mais usuais do que o registrado nos estudos atuais. Em terceiro lugar, ele possibilita obter uma conclusão sociológica com implicações políticas: a redistribuição econômica é uma condição necessária, mas não suficiente para uma redução multidimensional da desigualdade.

Palavras-chave Política linguística, Desigualdade, Hierarquias, Identidades, Classificações, Prestígio, Petroleiros.

\section{Abstract}

The article analyzes a situation in the Patagonian city of Comodoro Rivadavia in which strongly stigmatized workers have higher income levels than those stigmatizing them, resulting in a mismatch between symbolic hierarchies and socioeconomic class. Based on a shared interest in social inequalities and the ways in which these are culturally legitimized, the research pursued by the two authors - one an anthropologist from Buenos Aires and the other an anthropologist from the region in question shows how an exceptional case like Comodoro can shed new light on the traits of supposedly 'normal' cases where hierarchies of prestige are more or less match income levels. Furthermore the study reveals that cases in which this correlation is not the rule are actually more common than currently registered in the literature. Finaly the work enables us to reach a sociological conclusion with policy implications: economic redistribution is a necessary but insufficient condition for a multidimensional reduction of inequality.

Key words Linguistic Politics, Inequality, Hierarchy, Identity, Classification, Prestige, Oil Workers. 